\title{
Reflecting on Mechanical Functionalities in Bioreactors for Tissue Engineering Purposes
}

\author{
M. Hanif Nadhif ${ }^{1,2}$, Hanif Assyarify², Affan Kaysa Waafi' ${ }^{3}$, Yudan Whulanza, ${ }^{4,5,6,{ }^{*}}$ \\ ${ }_{1}^{1}$ Department of Medical Physics, Faculty of Medicine, Universitas Indonesia, JL. Salemba Raya No.6, Jakarta \\ 10340, Indonesia \\ ${ }^{2}$ Medical Technology Cluster, Indonesia Medical Education and Research Institute (IMERI), Faculty of \\ Medicine, Universitas Indonesia, JL. Salemba Raya No.6, Jakarta 10340, Indonesia \\ ${ }^{3}$ Department of Mechanical Engineering, Technical University of Denmark, Lyngby 2800, Denmark \\ ${ }^{4}$ Department of Mechanical Engineering, Faculty of Engineering, Universitas Indonesia, Kampus UI Depok, \\ Depok 16424, Indonesia \\ ${ }^{5}$ Research Center for Biomedical Engineering (RCBE), Universitas Indonesia, Kampus UI Depok, Depok 16424, \\ Indonesia \\ ${ }^{6}$ Stem Cell \& Tissue Engineering Cluster, Indonesia Medical Education and Research Institute (IMERI), Faculty \\ of Medicine, Universitas Indonesia, JL. Salemba Raya No.6, Jakarta 10340, Indonesia
}

\begin{abstract}
Many articles have reported a correlation between the use of mechanical stimulation and an enhancement in cultivation of various tissues engineered in bioreactors. The enhancement includes improvements in cell growth, proliferation, and functionalities. The aim of this report is to review the mechanical functionalities of tissue engineering bioreactors in terms of the forms of stimulation, types of stress, actuators, supporting modules, and, most importantly, efficacy. The Google Scholar database was searched for relevant articles. Three forms of simulation were reported: uniaxial, biaxial, and multiaxial. The types of stress exerted by bioreactors include compression, tension, shear, and dynamic stresses, which are applied solely or mutually depending on the number of axes involved. Mechanical stimulation could be actuated by stepper motors, pistons, pneumatic pumps, diaphragm pumps, piezoelectric systems, or dielectric charges. Additional modules, such as incubators, flow perfusion systems, ultrasound sensors, movement controls, and electrodes, can also support the mechanical functions of bioreactors. The efficacy of a bioreactor could be determined by investigating the biomechanical and histological properties of the engineered tissues. To facilitate the development of mechanical functionalities for tissue engineering bioreactors in the future, a seven-step framework is proposed.
\end{abstract}

Keywords: Bioreactors; Mechanical functionalities; Tissue engineering

\section{Introduction}

Tissue engineering has resulted in significant enhancements in medicine. At present, engineered tissues initially developed in labs are now used in clinics. The outcomes were a manifestation of a tissue engineering triad: cells, scaffolds, and signals (Birla, 2014). In terms of signals, abundant signal types and provisions, are now implemented for engineered tissues (Birla, 2014). One of the common provisions has been the use of bioreactors. Compared to petri dishes, bioreactors performed superior for tissue culture 
functions, as they allowed for dynamic (Nadhif et al., 2017) and three-dimensional culture of tissues (Heher et al., 2015), as well as providing the possibility of mechanical stimulation (Anderson and Johnstone, 2017). Mechanical stimulations are important for in vitro tissue engineering as they model the mechanical perturbations received by the tissues in vivo. The absence of mechanical stimulation in vitro may result in deviations in mechanical properties of the final cultured tissues, thereby causing deviations in the expected tissue models.

One of the first bioreactors that utilized a mechanical stimulation module was produced in the late 1990s (Vunjak-Novakovic et al., 1999). This group engineered cartilage constructs in rotating vessels, which imposed a shear stress induced by a dynamic laminar flow field. The resulting engineered cartilage constructs showed a higher fraction of collagen and glycosaminoglycans when compared to a static culture. Moreover, the artificial cartilage also showed better mechanical properties. After this finding, reports flourished regarding the use of mechanical stimulations in tissue engineering bioreactors. In most cases, mechanical stimuli were used to induce the growth and proliferation of dermatomusculoskeletal and cardiac muscle tissues, including skin (Helmedag et al., 2015), heart muscles (Mooney et al., 2012), cartilage (Vainieri et al., 2018), bones (Rauh et al., 2011), and skeletal muscles (Heher et al., 2015).

As first reported by Vunjak-Novakovic et al. (1999), the outcomes of mechanically stimulating bioreactors are often characterized by the mechanical properties of the tissues, the cell growth and proliferation, and the presence of extracellular matrix (ECM). The beating performance of the seeded cells are also considerations in engineered heart muscles (Shachar et al., 2012; Paez-Mayorga et al., 2019).

Unfortunately, reviews about the mechanical functionalities in tissue engineering bioreactors are still scattered. The existing reports mostly focus on one type of stress or one target tissue. For instance, a review by McCoy and O'Brien (2010) focused on the shear stress in bone tissue bioreactors, while a review by Anderson and Johnstone (2017) focused more on compression stress for engineered chondrocytes. A comprehensive review about various forms of mechanical stimulations for broad types of tissues is still lacking, not to mention the forms of loading and other related technical aspects.

The aim of this report was to review the mechanical functionalities for tissue engineering bioreactors in terms of the forms of stimulation, types of stress, actuators, supporting modules, and, most importantly, efficacy.

\section{Methods}

The review was initiated by collecting papers from the Google Scholar database. Several keywords were used, including "mechanical bioreactor," "mechanical stimulation bioreactor," and "mechanical tissue bioreactor." The paper recommendation when opening a paper page (i.e., in the Elsevier and PubMed databases) was also of consideration. Subsequently, the retrieved papers were sorted manually in terms of relevance and contextuality by thorough reading. Accordingly, the decision was made for inclusion or exclusion of a paper from the review. After the paper collection was considered sufficient, the papers were evaluated for important pieces of information, including the forms of stress, types of stress, actuators, supporting modules, and efficacy.

To facilitate the reading, the Results and Discussion chapter has been divided according to the forms of loading. The other pieces of information are further elaborated in each subchapter. At the end of the chapter, each component is discussed. 


\section{Results and Discussion}

The collected articles revealed three forms of stimulation: uniaxial, biaxial, and multiaxial. These three forms of stimulation are applied in 13 derived mechanisms (Table 1).

Table 1 Summary of mechanical functionalities in bioreactors

\begin{tabular}{|c|c|c|c|c|c|}
\hline $\begin{array}{c}\text { Form of } \\
\text { stimulation }\end{array}$ & Actuator & Type of force & $\begin{array}{l}\text { Cultured } \\
\text { specimen }\end{array}$ & $\begin{array}{l}\text { Supporting } \\
\text { modules }\end{array}$ & Ref \\
\hline \multirow{5}{*}{ Uniaxial } & Hip Ball & $\begin{array}{l}\text { Compressive, } \\
\text { shear }\end{array}$ & $\begin{array}{l}\text { Osteochondral } \\
\text { defect models }\end{array}$ & $\begin{array}{l}\text { Incubator (thermal } \\
\text { \& gas) }\end{array}$ & $\begin{array}{l}\text { (Vainieri et al., } \\
\text { 2018) }\end{array}$ \\
\hline & Piston & $\begin{array}{l}\text { Compressive, } \\
\text { shear }\end{array}$ & $\begin{array}{l}\text { Cardiac muscle } \\
\text { tissues }\end{array}$ & $\begin{array}{l}\text { Medium perfusion, } \\
\text { Incubator (thermal } \\
\text { \& gas) }\end{array}$ & $\begin{array}{l}\text { (Shachar et al., } \\
\text { 2012) }\end{array}$ \\
\hline & Piston & Flexural & TEHV scaffold & $\begin{array}{l}\text { Incubator (thermal } \\
\& \text { gas) }\end{array}$ & $\begin{array}{l}\text { (Engelmayr et } \\
\text { al., 2003) }\end{array}$ \\
\hline & $\begin{array}{l}\text { Piezoelectric } \\
\text { actuator }\end{array}$ & Compressive & Cartilage & $\begin{array}{l}\text { Medium perfusion, } \\
\text { incubator }\end{array}$ & $\begin{array}{l}\text { (Meyer et al., } \\
\text { 2006) }\end{array}$ \\
\hline & Motor & Tensile & Skin & $\begin{array}{l}\text { Incubator (thermal } \\
\text { \& gas) }\end{array}$ & $\begin{array}{l}\text { (Ladd et al., } \\
\text { 2009) }\end{array}$ \\
\hline \multirow{4}{*}{ Biaxial } & Motor & Tensile & Fibroblast & $\begin{array}{l}\text { Incubator (thermal } \\
\text { \& gas) }\end{array}$ & $\begin{array}{l}\text { (Bai et al., } \\
\text { 2014) }\end{array}$ \\
\hline & Motor & $\begin{array}{l}\text { Compressive, } \\
\text { shear }\end{array}$ & Cartilage model & $\mathrm{N} / \mathrm{A}$ & $\begin{array}{l}\text { (Yusoff et al., } \\
\text { 2011) }\end{array}$ \\
\hline & Motor & $\begin{array}{l}\text { Compressive, } \\
\text { shear }\end{array}$ & Cartilage model & $\begin{array}{l}\text { Incubator (thermal } \\
\text { \& gas), force } \\
\text { feedback, } \\
\text { positional feedback }\end{array}$ & $\begin{array}{l}\text { (Bilgen et al., } \\
\text { 2013) }\end{array}$ \\
\hline & Piston & $\begin{array}{l}\text { Compressive, } \\
\text { shear }\end{array}$ & Cartilage model & $\begin{array}{l}\text { Incubator (thermal } \\
\text { \& gas) }\end{array}$ & $\begin{array}{l}\text { (Meinert et al., } \\
\text { 2017) }\end{array}$ \\
\hline \multirow{4}{*}{ Multiaxial } & $\begin{array}{l}\text { Pneumatic } \\
\text { Pump }\end{array}$ & Tensile & Cancer cell lines & $\begin{array}{l}\text { Electrode } \\
\text { (recording) }\end{array}$ & $\begin{array}{l}\text { (Pakazad et al., } \\
\text { 2014) }\end{array}$ \\
\hline & $\begin{array}{l}\text { Pneumatic } \\
\text { Pump }\end{array}$ & Tensile & $\begin{array}{l}\text { Vascular-derived } \\
\text { tissue construct }\end{array}$ & Ultrasound sensor & $\begin{array}{l}\text { (van Kelle et al., } \\
\text { 2017) }\end{array}$ \\
\hline & $\begin{array}{l}\text { Diaphragm } \\
\text { Pump }\end{array}$ & Tensile & $\begin{array}{l}\text { MSC-seeded } \\
\text { hydrogel }\end{array}$ & $\begin{array}{l}\text { Electrode } \\
\text { (recording), } \\
\text { Incubator (thermal } \\
\text { \& gas) }\end{array}$ & $\begin{array}{l}\text { (Liu et al., } \\
\text { 2018) }\end{array}$ \\
\hline & $\begin{array}{l}\text { Dielectric } \\
\text { Elastomer } \\
\text { Actuator } \\
\text { (DEA) }\end{array}$ & Tensile & Fibroblasts & $\begin{array}{l}\text { Incubator (thermal } \\
\text { \& gas) }\end{array}$ & $\begin{array}{l}\text { (Costa et al., } \\
\text { 2020) }\end{array}$ \\
\hline
\end{tabular}

\subsection{Uniaxial Stimulation}

As the name implies, uniaxial mechanical stimulation works with actuators that move in one single axis in the bioreactor. Uniaxial stress has been realized with varied types of stress; in fact, even for the same type of stress, the actuator used can differ.

One of the earliest uniaxial bioreactors was reported by Engelmayr et al. (2003). That group utilized a piston-motor system positioned parallel to two 6-well plates for the culture 
of tissue-engineered heart valve (TEHV) scaffolds (Figure 1a). The piston-motor system was connected to a cross-arm that had stirrers inside each well of the well plates. This mechanism successfully generated cyclic loading in the form of dynamic flexure. The dynamic flexure significantly affected the effective stiffness of the TEHV scaffolds when compared with static loading. Qualitative analysis using scanning electron microscopy (SEM) showed a more pronounced fragmentation of fibers in the scaffold mesh in the cyclically loaded culture (Engelmayr et al., 2003).

Another uniaxial stress stimulation was provided by delivering a compressive stress using different types of actuators (Figure 1b). The first mode used a piezoelectric-driven loading system (Meyer et al., 2006). In that study, the loading system was perpendicular to a three-dimensional culture of osteoblasts and chondrocytes and allowed a stamping mechanism to cyclically compress the specimens. The stamping system was claimed to induce the elongation of the specimens along the horizontal axis, in addition to the deformation in the $z$ direction. The dynamic culture of specimens was enabled by installing an open loop pumping system for culture medium supply and waste removal. Mechanical loads over extended periods increased the proliferation and differentiation of osteoblasts and chondrocytes.

Compressive stress has also been generated using a crankshaft engine that lifted and lowered the 48-piston platform (Shachar et al., 2012). The 48-piston platform was positioned precisely on top of a 48-well plate, which functioned as a locus for cardiac tissue engineering. The growth of the engineered cardiac tissue was supported by liquid medium poured into each well. The presence of liquid medium suggested the presence of another type of stress, and the group used a fluent computational fluid dynamic (CFD) software to also evaluate the shear stress due to the fluid flow when the piston was lowered into the medium. The cyclic compression, followed by perfusion-associated shear stress, promoted cardiac tissue regeneration that showed organized myofibrils and the striation of an adult heart muscle tissue. The results implied that this type of stimulation generated a better model of an in vivo adult tissue.

Compressive stress has also been imposed by setting up an actuator that imitates an active part of the body that delivers stress to the tissue of interest. Vainieri et al. (2018) imitated a femoral head using a ceramic hip ball, which was coupled with an actuator to deliver a cyclic compressive stress to osteochondral defect models (Figure 1c). Simultaneous shear motions were also observed during the compression due to the ball oscillation. The dynamic compression and oscillation-induced shear stress did not wear out the cartilage model. The gene expression by the cultured chondrocytes suggested a chondrogenic response to the mechanical stimuli. These results obtained from the hip ball mechanism were expected to clarify the mechanobiology of the recovery of osteochondral defects, as well as to uncover the mechanical signaling regarding the correlation between molecular signaling and treatment (Vainieri et al., 2018).

In contrast to the uniaxial stimulations, which were mostly compressive, Ladd et al. (2009) used a tensile stress to evaluate the effects of in vitro stretching of skin matrices (Figure 1d). The tensile stress was generated by a motor actuator that elongated the skin gradually for approximately 5 days. The expanded skin matrices showed the viscoelastic properties common to skin, including a higher Young's modulus and tensile stress compared to control matrices. The bioreactor system maintained cell viability and proliferation, upheld the dermal structural integrity, and increased the pore size, which allowed expansion of the size of skin flaps for reconstructive surgeries. 


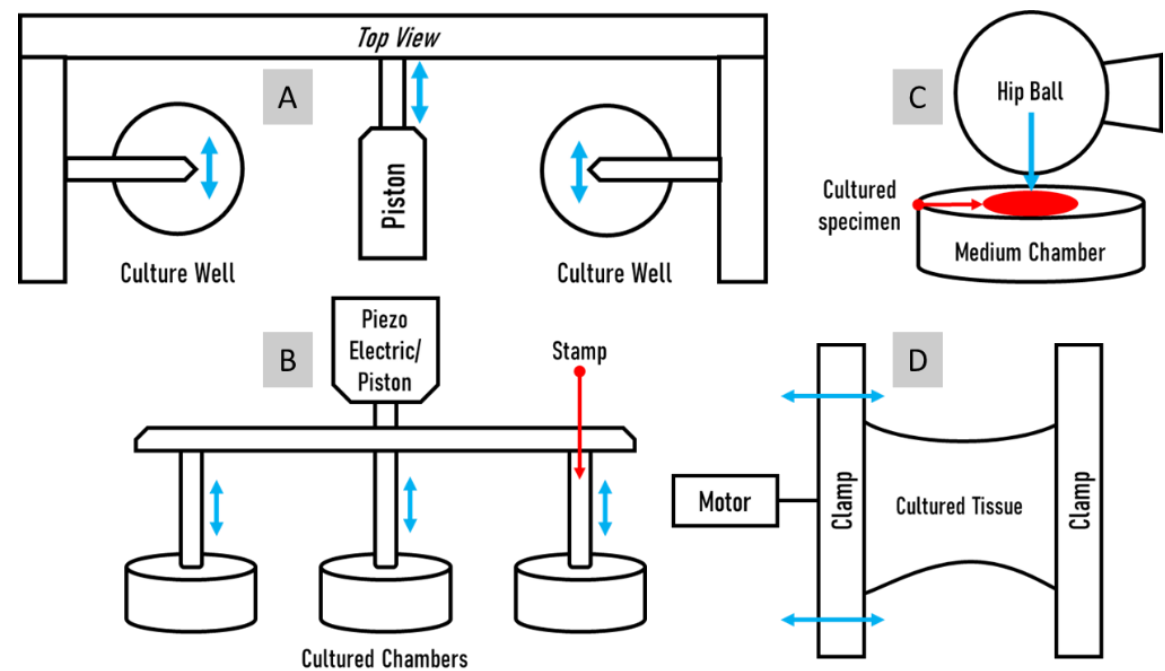

Figure 1 Forms of uniaxial stimulations: parallel piston (a), perpendicular piston (b), hip ball mechanism (c), and stretch clamp (d)

In some articles, although the designated stress was set to work in one axis, the authors claimed that another stress was working on another axis due to the manifestation of the main stress. Shachar et al. (2012) backed up this claim using CFD analysis and reported that the piston compression toward the culture medium triggered flow perfusion in the vicinity of the cultured tissue. The fluid velocity vectors were also presented in the article. Nevertheless, the paper lacks the experimental characterization of shear stress, which would seem to make the claim about the shear stress incomplete. Similarly, Vainieri et al. (2018) only mentioned that the emerged shear stress was due to the oscillation of the hip ball; they failed to elaborate further on the shear stress. A characterization of shear stress was also absent, which made the claim about the presence of shear stress equivocal.

\subsection{Biaxial Stimulation}

Although some uniaxially stimulating bioreactors are able to generate biaxial stress, the stress working in the second axis is typically the reverberation of the main working stress. This subchapter describes biaxial stimulation that was intended from the beginning of the bioreactor design. The reason for this development was the need to mimic the in vivo environment more accurately, since most soft tissues experience complex multiaxial loading in vivo (Huang et al., 2015).

The first biaxial stimulation was designed by combining an actuator system generating the compressive stress and an actuator generating shear stress perpendicular and parallel to the cultured specimens, respectively (Figure 2a). Yusoff et al. (2011) generated a compressive stress using two stepper motors connected to power screw shafts, thereby converting the rotation motion of the motor into the linear motion of the piston system perpendicular to the culture plate. Meanwhile, another motor was placed in parallel with the culture plate to generate shear stress. Although this bioreactor was not tested with living tissues, the technical validation showed the ability of the bioreactor to generate sinusoidal and intermittent loads to the culture plate. The reliability test conducted by applying dynamic loading with 99,999 cycles resulted in significantly similar compression and shear to that observed with the first dynamic load. Moreover, the stress distribution patterns of the modelled cartilage, determined using finite element methods (FEM), proved that the biaxial loading resulted in more uniform distribution than was achieved with uniaxial loading. 
A compression-shear stimulation system has already been employed in the assessment of artificial cartilages (Bilgen et al., 2013). This system was also equipped with a load cell and linear optic encoders to provide the force feedback and positional feedback, respectively. In terms of results, the glycosaminoglycan (GAG) and collagen contents of the artificial cartilage were more profound in the biaxial loading group than in the uniaxial and control groups. A latter report also confirmed the abundance of GAG and collagen in the artificial cartilage (Meinert et al., 2017).

Biaxial stimulation can also be implemented using a biaxial tensile system. This system is an improvement over the uniaxial tension system. Instead of using only a single motor, the biaxial tension system used two motors, each working in a separate axis (Figure 2b). Bai et al. (2014) used this system to construct a three-dimensional culture of fibroblasts in cruciform fibrin-collagen gels. Every end of the cruciform matrix was clamped to the biaxial tensile system, thereby allowing cyclic tension. After a 31-day culture, the seeded cells and deposited collagen were arbitrarily, yet equibiaxially, distributed in the matrix. Surprisingly, both matrices with biaxial stretch and control presented isotropic mechanical properties and progressively increasing stiffness, regardless of the difference in the collagen microstructure (Bai et al., 2014).
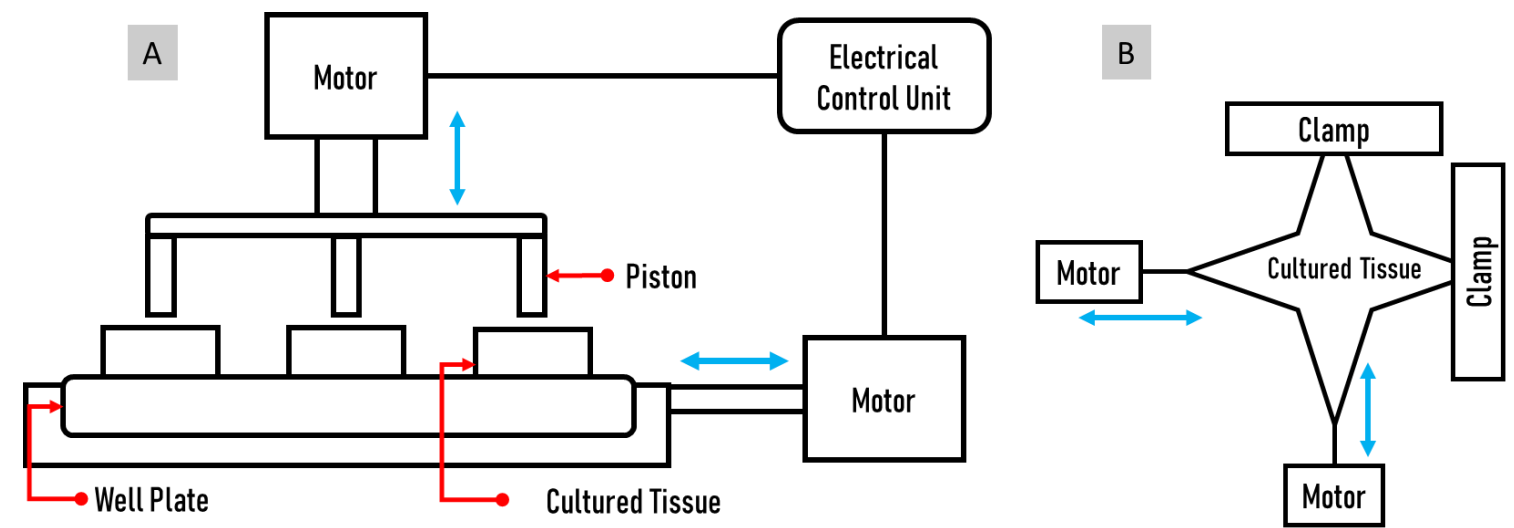

Figure 2 Forms of biaxial stimulations: compression-shear system (a) and biaxial tension system (b)

\subsection{Multiaxial Stimulation}

Multiaxial stimulation can be realized by forming the matrix, scaffold, or substrate as a free-standing membrane. Subsequently, the membrane is inflated and deflated, which generates a bulging mechanism that stimulates the cultured tissue multiaxially. The mechanical properties of the free-standing membrane were characterized using the bulge test equation (Oomen et al., 2017; van Kelle et al., 2017).

One approach used to realize a bulging mechanism was to deliver pneumatic pressure to the back side of the membrane (Figure 3a). The polydimethylsiloxane (PDMS) membranes used by Pakazad et al. (2014) and by Liu et al. (2018) were permanently intact parts of the bioreactor, meaning that membrane replacement during use was impossible. Liu et al. (2018) used a bioreactor membrane that enabled the culture of tissue scaffolds. By contrast, the membrane used by Pakazad et al. (2014) limited cell culture only to the microgrooves on the top of the membrane.

The integrated membrane-bioreactor as one monolithic design also allowed the addition of other modules to the bioreactor. Liu et al. (2018) fabricated carbon nanotube (CNT) strain sensor sensors inside the membrane to allow for mechanical stimulation and stiffness measurements of the tissue constructs. Similarly, Pakazad et al. (2014) also 
embedded electrodes into the membrane during the fabrication to allow recording of the electrophysiological behavior of the cultured cells.

The bulging mechanism could also be implemented using a changeable membrane (Shen et al., 2017; van Kelle et al., 2017), which was in the form of a cell-seeded scaffold. Before the bioreactor was operated, the membrane was clamped within the bioreactor. However, prior to the cyclic loading application, van Kelle et al. (2017) cultured the membrane of tissue constructs statically in 6-well plates to strengthen the mechanical integrity of the tissue constructs. During bulging, the mechanical properties of the tissue constructs were investigated. The results showed that this type of bioreactor could allow for in vitro tissue modeling and for adjustable mechanical functionalities.

Hydrostatically coupled dielectric elastomer actuators (HC-DEAs) have also been used. The bubble-like structure of the HC-DEA was formed upward when the voltage was applied. A HC-DEA-based bioreactor successfully promoted the orientation of the cytoskeleton (Costa et al., 2020) as a result of an $8 \mathrm{~h}$ cyclic stretching of the membrane. The orientation also showed a perpendicular tendency toward the radial stretch direction.
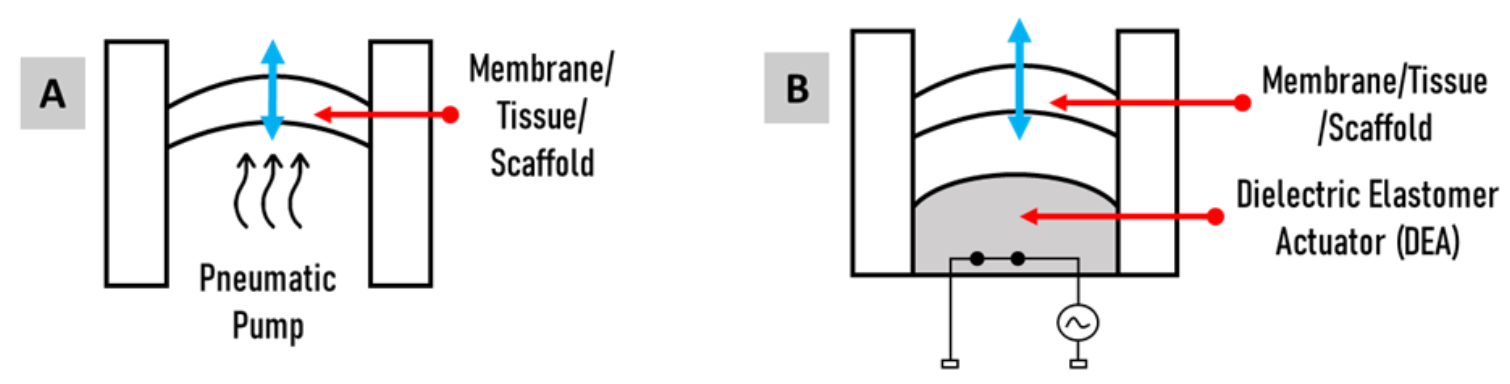

Figure 3 Forms of multiaxial stimulations using a pneumatic pump (a) and using a dielectric elastomer actuator (b)

\subsection{Recommendations}

The variation in the methodologies used to develop mechanical functionalities in the reviewed papers emphasized the importance of gathering and denoting the crucial aspects of the mechanical functionalities. Subsequently, these crucial aspects were synthesized into a stepwise framework consisting of seven steps. The first step is designing the parts of the mechanical module (i.e., the chamber holding the specimens, the actuating mechanism, and the casing) using computer-aided design (CAD) software (Yusoff et al., 2011; Helmedag et al., 2015). The CAD design can also be used to model an engineered tissue for FEM and CFD simulations (Shen et al., 2017). The second step is simulation of the stresses acting on the cultured specimens using CFD and FEM. CFD can be used to simulate stress induced by flow perfusion (Shachar et al., 2012), while FEM can be used to simulate stress imposed by solid contacts, such as compression and tension (Yusoff et al., 2011; Shen et al., 2017). The third step is to design a control system, which may feature force feedback and positional feedback, thereby stabilizing the mechanical stimulation (Bilgen et al., 2013; Liu et al., 2018). Moreover, researchers may implement genetic algorithm in the control system to optimize the motor movement (Soesanto et al., 2018).

The fourth step is the implementation and assembly of the mechanical modules with biocompatible manufacturing techniques and materials; the choice depends on the output engineered tissue, as well as the tissue functionalities. In parallel with the fourth step, additional modules can be performed to support the functions of the bioreactor, as presented in Table 1. The use of incubator for thermal preservation, nonetheless, might be replaced by integrating a thermal module in a bioreactor (Nadhif et al., 2019). Another 
module that can be integrated is the medium perfusion, which may use a peristaltic pump (Xiao et al., 2014), a syringe pump (McCoy and O'Brien, 2010), and a mechanical mixer (Qian et al., 2016). Before implementing the medium perfusion module, researchers can carry out CFD to analyze the output flow rate and pressure (Muharam and Kurniawan, 2016), as well as the effect of the perfusion flow to the cultured tissue.

The fifth step is the biomechanical characterization of the bioreactors and cultured tissues. For instance, in the multiaxial bioreactor, the pressure delivered by the pneumatic pump is correlated with the resulting strain of the membrane (Pakazad et al., 2014). In terms of tissue biomechanics, the evaluation includes the tissue elastic modulus, tensile stress, strain, microstructure, and porosity, as well as the abundance and microstructure of the ECM. The final step is the histological testing of the engineered tissues, including cell viability, cell proliferation, cell differentiation, tissue regeneration, gene expression, and electrophysiological behavior.

\section{Conclusions}

The mechanical functionalities of bioreactors can be divided into three forms of stimulation: uniaxial, biaxial, and multiaxial. The uniaxially stimulating bioreactors produce stresses that are compressive, tensile, shear, and flexural. Some articles have claimed that the uniaxial stimulation they developed could result in biaxial stress. However, that claim should be thoroughly scrutinized since the articles lacked any experimental characterizations. Most biaxial stimulations combined compression and shear, although that type of stimulation could also exist as a biaxial tension. The multiaxial system has been characterized using the bulging mechanism, actuated by a pneumatic system acting on a dielectric elastomer. To facilitate future work in developing mechanical functionalities of tissue engineering bioreactors, a seven-step framework is proposed.

\section{Acknowledgements}

This research was supported by the Universitas Indonesia Grant PIT9 in 2019 with Contract Number: NKB-0084/UN2.R3.1/HKP.05.00/2019.

\section{References}

Anderson, D. E., Johnstone, B., 2017. Dynamic Mechanical Compression of Chondrocytes for Tissue Engineering: A Critical Review, Frontiers in Bioengineering and Biotechnology, Volume 5, p. 76

Bai, Y., Po-Feng Lee, Jay D. Humphrey, Alvin T. Yeh, 2014. Sequential Multimodal Microscopic Imaging and Biaxial Mechanical Testing of Living Multicomponent Tissue Constructs, Annals of Biomedical Engineering, Volume 42(9), pp. 1791-1805

Bilgen, B., Chu, D., Stefani, R., Aaron, R. K., 2013. Design of a Biaxial Mechanical Loading Bioreactor for Tissue Engineering, Journal of Visualized Experiments, Volume (74), p. 50387

Birla, R., 2014. Introduction to Tissue Engineering: Applications and Challenges, Wiley-IEEE Press. pp. 1-327

Costa, J., Ghilardi, M., Mamone, V., Ferrari, V., Busfield, J. J. C., Ahluwalia, A., Carpi, F., 2020. Bioreactor with Electrically Deformable Curved Membranes for Mechanical Stimulation of Cell Cultures, Frontiers in Bioengineering and Biotechnology, Volume 8, pp. 1-9 
Engelmayr, G. C., Hildebrand, D. K., Sutherland, F. W. H., Mayer, J. E., Sacks, M. S., 2003. A Novel Bioreactor for the Dynamic Flexural Stimulation of Tissue Engineered Heart Valve Biomaterials, Biomaterials, Volume 24(14), pp. 2523-2532

Heher, P., Maleiner, B., Prüller, J., Teuschl, A. H., Kollmitzer, J., Monforte, X., Wolbank, S., Redl, H., Rünzler, D., Fuchs, C., 2015. A Novel Bioreactor for the Generation of Highly Aligned 3D Skeletal Muscle-like Constructs through Orientation of Fibrin via Application of Static Strain, Acta Biomaterialia, Volume 24, pp. 251-265

Helmedag, M. J., Weinandy, S., Marquardt, Y., Baron, J. M., Pallua, N., Suschek, C. V., Jockenhoevel, S., 2015. The Effects of Constant Flow Bioreactor Cultivation and Keratinocyte Seeding Densities on Prevascularized Organotypic Skin Grafts Based on a Fibrin Scaffold, Tissue Engineering Part A, Volume 21(1-2), pp. 343-352

Huang, A. H., Lee, Y.-U., Calle, E. A., Boyle, M., Starcher, B. C., Humphrey, J. D., Niklason, L. E., 2015. Design and Use of a Novel Bioreactor for Regeneration of Biaxially Stretched Tissue-Engineered Vessels, Tissue Engineering Part C: Methods, Volume 21(8), pp. 841-851

van Kelle, M. A. J., Oomen, P. J. A., Bulsink, J. A., Janssen-van den Broek, M. W. J. T., Lopata, R. G. P., Rutten, M. C. M., Loerakker, S., Bouten, C. V. C., 2017. A Bioreactor to Identify the Driving Mechanical Stimuli of Tissue Growth and Remodeling, Tissue Engineering Part C: Methods, Volume 23(6), pp. 377-387

Ladd, M. R., Lee, S. J., Atala, A., Yoo, J. J., 2009. Bioreactor Maintained Living Skin Matrix, Tissue Engineering Part A, Volume 15(4), pp. 861-868

Liu, H., MacQueen, L. A., Usprech, J. F., Maleki, H., Sider, K. L., Doyle, M. G., Sun, Y., Simmons, C. A., 2018. Microdevice Arrays with Strain Sensors for 3D Mechanical Stimulation and Monitoring of Engineered Tissues, Biomaterials, Volume 172, pp. 30-40

McCoy, R. J., O’Brien, F. J., 2010. Influence of Shear Stress in Perfusion Bioreactor Cultures for the Development of Three-Dimensional Bone Tissue Constructs: A Review, Tissue Engineering Part B: Reviews, Volume 16(6), pp. 587-601

Meinert, C., Schrobback, K., Hutmacher, D. W., Klein, T. J., 2017. A Novel Bioreactor System for Biaxial Mechanical Loading Enhances the Properties of Tissue-Engineered Human Cartilage, Scientific Reports, Volume 7(1), p. 16997

Meyer, U., Büchter, A., Nazer, N., Wiesmann, H. P., 2006. Design and Performance of a Bioreactor System for Mechanically Promoted Three-Dimensional Tissue Engineering, British Journal of Oral and Maxillofacial Surgery, Volume 44(2), pp. 134-140

Mooney, E., Mackle, J. N., Blond, D. J. P., O’Cearbhaill, E., Shaw, G., Blau, W. J., Barry, F. P., Barron, V., Murphy, J. M., 2012. The Electrical Stimulation of Carbon Nanotubes to Provide a Cardiomimetic Cue to MSCs, Biomaterials, Elsevier Ltd, Volume 33(26), pp. 6132-6139

Muharam, Y., Kurniawan, A., 2016. Computational Fluid Dynamic Application in Scale-up of a Stirred-Batch Reactor for Degumming Crude Palm Oil, International Journal of Technology, Volume 7(8), pp. 1344-1351

Nadhif, M. H., Hadiputra, A. P., Utomo, M. S., Whulanza, Y., 2019. Fabrication and Characterization of an Affordable Conditioned Bio-Specimen Transporter (Conbiport) for Urban Areas, International Journal of Technology, Volume 10(8), pp. 1626-1634

Nadhif, M. H., Whulanza, Y., Istiyanto, J., Bachtiar, B. M., 2017. Delivery of Amphotericin B to Candida Albicans by Using Biomachined Lab-on-a-Chip, Journal of Biomimetics, Biomaterials and Biomedical Engineering, Volume 30, pp. 24-30 
Oomen, P. J. A., van Kelle, M. A. J., Oomens, C. W. J., Bouten, C. V. C., Loerakker, S., 2017. Nondestructive Mechanical Characterization of Developing Biological Tissues Using Inflation Testing, Journal of the Mechanical Behavior of Biomedical Materials, Volume 74, pp. 438-447

Paez-Mayorga, J., Hernández-Vargas, G., Ruiz-Esparza, G. U., Iqbal, H. M. N., Wang, X., Zhang, Y. S., Parra-Saldivar, R., Khademhosseini, A., 2019. Bioreactors for Cardiac Tissue Engineering, Advanced Healthcare Materials, Volume 8(7), p. 1701504

Pakazad, S. K., Savov, A., van de Stolpe, A., Dekker, R., 2014. A Novel Stretchable MicroElectrode Array (SMEA) Design for Directional Stretching of Cells, Journal of Micromechanics and Microengineering, Volume 24(3), p. 034003

Qian, X., Nguyen, H. N., Song, M. M., Hadiono, C., Ogden, S. C., Hammack, C., Yao, B., Hamersky, G. R., Jacob, F., Zhong, C., Yoon, K., Jeang, W., Lin, L., Li, Y., Thakor, J., Berg, D. A., Zhang, C., Kang, E., Chickering, M., Nauen, D., Ho, C.-Y., Wen, Z., Christian, K. M., Shi, P.-Y., Maher, B. J., Wu, H., Jin, P., Tang, H., Song, H., Ming, G., 2016. Brain-Region-Specific Organoids Using Mini-Bioreactors for Modeling ZIKV Exposure, Cell, Volume 165(5), pp. $1238-1254$

Rauh, J., Milan, F., Günther, K.-P., Stiehler, M., 2011. Bioreactor Systems for Bone Tissue Engineering, Tissue Engineering Part B: Reviews, Volume 17(4), pp. 263-280

Shachar, M., Benishti, N., Cohen, S., 2012. Effects of Mechanical Stimulation Induced by Compression and Medium Perfusion on Cardiac Tissue Engineering, Biotechnology Progress, Volume 28(6), pp. 1551-1559

Shen, N., Knopf, A., Westendorf, C., Kraushaar, U., Riedl, J., Bauer, H., Pöschel, S., Layland, S. L., Holeiter, M., Knolle, S., Brauchle, E., Nsair, A., Hinderer, S., Schenke-Layland, K., 2017. Steps toward Maturation of Embryonic Stem Cell-Derived Cardiomyocytes by Defined Physical Signals, Stem Cell Reports, Volume 9(1), pp. 122-135

Soesanto, Q. M. B., Widiyanto, P., Susatyo, A., Yazid, E., 2018. CASCADE OPTIMIZATION OF AN AXIAL-FLOW HYDRAULIC TURBINE TYPE PROPELLER BY A GENETIC ALGORITHM, International Journal of Technology, Volume 10(1), pp. 200-211

Vainieri, M. L., Wahl, D., Alini, M., van Osch, G. J. V. M., Grad, S., 2018. Mechanically Stimulated Osteochondral Organ Culture for Evaluation of Biomaterials in Cartilage Repair Studies, Acta Biomaterialia, Volume 81, pp. 256-266

Vunjak-Novakovic, G., Martin, I., Obradovic, B., Treppo, S., Grodzinsky, A. J., Langer, R., Freed, L. E., 1999. Bioreactor Cultivation Conditions Modulate the Composition and Mechanical Properties of Tissue-Engineered Cartilage, Journal of Orthopaedic Research, Volume 17(1), pp. 130-138

Xiao, Y., Zhang, B., Liu, H., Miklas, J. W., Gagliardi, M., Pahnke, A., Thavandiran, N., Sun, Y., Simmons, C., Keller, G., Radisic, M., 2014. Microfabricated Perfusable Cardiac Biowire: A Platform That Mimics Native Cardiac Bundle, Lab Chip, Volume 14(5), pp. 869-882

Yusoff, N., Abu Osman, N. A., Pingguan-Murphy, B., 2011. Design and Validation of a Bi-Axial Loading Bioreactor for Mechanical Stimulation of Engineered Cartilage, Medical Engineering \& Physics, Volume 33(6), pp. 782-788 